\title{
A sociologia de um gênero: o baião
}

(ALVES, Elder P. Maia. A sociologia de um gênero: o baião. Maceió: Edufal, 2012. 386 p.)

\author{
Clóvis Carvalho Britto* \\ "Eu já dancei balancê, \\ xamego, samba e xerém, \\ mas o baião tem um quê \\ que as outras danças não têm". \\ Baião, Luiz Gonzaga \& Humberto Teixeira.
}

Recebido: 21.03 .14

Aprovado: 28.08.14

\author{
* Doutor em \\ Sociologia pela \\ Universidade de \\ Brasília (UnB), \\ professor da \\ Universidade Federal \\ de Sergipe (UFS). \\ <clovisbritto5@ \\ hotmail.com>.
}

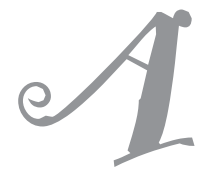

poesia resultante de composições como "Baião", de Luiz Gonzaga e Humberto Teixeira, associada ao peculiar ritmo oriundo das confluências entre zabumba, triângulo e sanfona, traduz o sentimento resultante da leitura do sensível e inquiridor trabalho de Elder P. Maia Alves intitulado A sociologia de um gênero: o baião. Trabalho, consagrado no Prêmio Funarte Centenário de Luiz Gonzaga 2012, consiste em uma espécie de continuidade das análises do pesquisador, cuja trajetória tem se dedicado a compreensão dos itinerários áridos e úmidos do sertão e das tramas poéticas e políticas da cultura popular sertanejo-nordestina (Alves, 2011; 2004). Todavia, é um projeto criativo que avança como um repertório marcado pelas inovações, abrindo espaço para a propositura de experimentações e para o reconhecimento de um estilo já evidenciado pelo público admirador de seu percurso epistemológico.

Conforme analisa Luciana Heymann (2004), as datas comemorativas não são dotadas de valor intrínseco, nem se justificam no passado. Seus significados resultam da atribuição de valor ao evento ou pessoa que se recorda, envolta nos imperativos do presente e nos lugares ocupados pelos agentes que comemoram. A importância de eventos de vigilância comemorativa como o centenário de Luiz Gonzaga, a instituição do prêmio pela Funarte e a própria edição da obra de Elder Alves, consiste em mecanismos que legitimariam ações em nome da memória (sobre qual leitura do passado e o monopólio do direito de falar sobre o passado), acionando, assim, a rede de economia simbólica em torno de determinadas pessoas e fatos, instituindo legados. No caso em análise, tais investimentos fortalecem a explosão discursiva, a 
conservação e a difusão da energia social que sustenta as tramas em torno do baião e da produção da crença em seus expoentes.

Inspirados pelos referenciais utilizados ao longo da pesquisa, concordamos com os argumentos explicitados no prefácio de Dmitri Fernandes quando sublinhou o advento de ferramentas heurísticas no congraçamento de uma renovação teórico-metodológica nos estudos de música, literatura e história no Brasil dos últimos anos. Especialmente na análise de um gênero musical que sociologicamente ainda não havia sido problematizado com o devido fôlego e profundidade como o baião. Nesse sentido, Elder Alves encaminha-nos a refletir sobre o modo como esse gênero alçou o posto de emblema da nacionalidade, desconstruindo muitas estratégias de fabricação dessa crença em uma perspectiva de longa duração.

O baião se torna por excelência uma explosão discursiva paradoxal ao contribuir para a invenção do Nordeste e ao extrapolar essa circunscrição geográfica, tornando-se um eixo significativo para a compreensão de algumas facetas do processo de modernização do Brasil, ou, como assinala o autor, para as bases do processo de industrialização do simbólico. Como bem destaca o pesquisador, dá-se o encontro entre os materiais sonoros atualizados e forjados por Luiz Gonzaga, Humberto Teixeira e Zé Dantas (a exemplo da aceleração do binarismo da polca e da mazurca e da influência do samba urbano) e os distintos aprendizados e experiências nos circuitos musicais do Rio de Janeiro em teatros, casas de show, programas no rádio e gravações de disco.

É por isso que optamos por iluminar o trocadilho eleito estrategicamente pelo autor ao intitular a obra como a sociologia de um gênero. Embora demonstre como também foram fundamentais as trajetórias de Humberto Teixeira e Zé Dantas, no processo de formação e consolidação do gênero musical, é inegável que o mesmo foi monumentalizado na figura emblemática daquele que se tornou entre diversas vigilâncias comemorativas e fabricações de crença o "Rei do Baião". Desse modo, o Nordeste, que se alastra para o restante do país e para fora dele através das trajetórias de migrantes, e os estilhaços desses trajetos em busca de ressonância são os protagonistas dessa obra que também inaugura, nas ciências sociais brasileiras, um profícuo ritmo analítico. Nesse aspecto, o trocadilho se torna apropriado por remeter-nos à Mozart: sociologia de um gênio (1995), de Norbert Elias. Para além da evidente herança teórico-metodológica da matriz eliasiana, as pesquisas assumem pontos de contato ao se tornarem importantes subsídios para a compreensão dos gêneros musicais, das trajetórias-processos dos artífices nos espaços simbólicos e sonoros-musicais, dos dispositivos psicossociais e das correspondentes pressões sociais. Guardadas as devidas proporções, Elder investiga Gonzagão e outros expoen- 
tes - trajetórias que se tornam metáfora e metonímia do baião - a partir de sua música e da figuração social demonstrando como a trajetória-corpo é constituída no (des)encontro com outros processos, forjando corpos-disposições.

O modo como o baião surge nesses interstícios, fruto do trânsito de quem cria os criadores, e a forma como forja uma identidade nacional na consolidação de uma "pauta auditiva e de uma memória musical" em torno de uma narrativa de sertão e da interpenetração entre arte, técnica, mercado e memória são os instrumentos que, em uníssono, acompanham a urdidura do livro. O autor evidencia uma perspicaz saída metodológica: o baião como uma espécie de gênero do entre-lugar, do intermezzo. Assim como as narrativas estampadas nas sonoras letras, o baião seria fruto da migração dos nordestinos, do encontro com a dinâmica sonoro-musical do Rio de Janeiro dos anos de 1940 e das reinvenções das memórias lúdico-orais de seus principais artífices. Confluências geradoras de uma

\begin{abstract}
nova estrutura de sensibilidade poético-melódica, capaz de reconhecer, no gênero e em seu consumo, um tradutor e um produtor legítimo e autorizado do imaginário telúrico do mundo rural brasileiro, cujas práticas e memórias se viam em profundas transformações (Alves, 2012: 21).
\end{abstract}

É certo que o intuito da obra não foi estabelecer uma análise biográfica de Luiz Gonzaga. Todavia, a posição que ocupou ao inaugurar o gênero e atualizá-lo na forma forró-baião contribuiu para que sua trajetória fosse evidenciada no campo musical. Soma-se a essa constatação, o fato de o advogado Humberto Teixeira e de o médico Zé Dantas terem, de certo modo, se invisibilizado em decorrência de sua atuação como compositores (ver Moreira, 2013), ao contrário de Gonzaga, que, além de compor, também protagonizava os palcos das disputas pela distinção do simbólico como sanfoneiro-cantor. O fato é que essas trajetórias sociais impactaram a própria trajetória do campo em que ousaram ocupar um lugar de fala e, mais do que isso, fabricar um vocabulário de motivos que possibilitasse um lugar onde pudessem entoar sua fala com autoridade. Para tanto, o autor destaca três investimentos fundadores desse projeto: a maturação da performance vocal de Luiz Gonzaga; a indumentária do vaqueiro-cangaceiro; e a formatação de um carismático cantor-cronista do sertão. Características que, de acordo com o pesquisador, não elidem o caráter criativo do cantor, instrumentista e compositor, mas

evidenciam a dinâmica reflexiva na qual estava envolvido, assim como as possibilidades de tomadas de decisão diante de um cipoal de processos estéticos, simbólicos, econômicos, subjetivos e objetivos (Alves, 2012: 245-246). 
Não sem motivos, a pesquisa também apresenta uma inspiração bourdieusiana, seja na eleição dos conceitos de saber incorporado e da trajetória, seja no esquadrinhamento das configurações em torno do campo de produção musical e de sua economia simbólica. As análises de Pierre Bourdieu (2005; 2004) foram sustentáculos na constituição do ponto de partida para a visualização de algumas feições do encontro entre economia e cultura, especialmente as estratégias de operacionalização de uma política da memória e de manipulação de recursos com vistas à fabricação e perpetuação da crença no baião enquanto poética do espaço e política da memória.

A investigação das formas de mobilização dos sentidos a partir de instâncias de produção, circulação e consagração contribui para a visualização dos bastidores e das cenas de um amplo empreendimento de alquimia social tecido pelos agentes envolvidos no campo de produção e circulação cultural ao fabricar e consagrar a autoridade do gênero musical. Desse modo, não foi sem motivos que o pesquisador esboçou os trânsitos simbólico-sonoros que possibilitaram a emergência do baião como gênero entre o mundo rural e urbano e as estratégicas estéticas e políticas de seus principais expoentes.

A primeira parte do livro consiste na reconstituição desse espaço de possíveis expressivos, apresentando os gêneros de matriz rural a exemplo do coco, da embolada e da moda de viola caipira para, em seguida, demonstrar as raízes e os rizomas do baião, a partir de suas especificidades: o não encapsulamento no rótulo de "música sertaneja/rural" ou "música folclórica" e as diversas condições sociológicas que permitiram aprendizados múltiplos e novos fluxos impactados pela industrialização do simbólico.

A montagem dos programas de rádio, as discussões de modernismo e nacionalismo musical, o esquadrinhamento do fazer musical e das formas de experimentação e fruição gestadas nos anos 1930 e 1940 são algumas das estratégias eleitas pelo autor para efetuar a história social de um projeto ou, em outras palavras, a análise dos investimentos sociais que transformaram o baião em um projeto estético-musical. O autor demonstra, desse modo, como o baião potencializou o processo de delimitação dos limites imagéticos culturais do sertão nordestino, construindo, assim, um monopólio de sentido e moeda de troca na construção da "nordestinidade". O baião constitui-se, ao mesmo tempo, em síntese e tradução:

Esta tradução imprimiu um novo registro sociocultural de identificação e significação do sertão nordestino: o lúdico. O sertão/ Nordeste passou, então, a significar também criação artística e, sobretudo, musical (Alves, 2012: 371).

A pesquisa de Elder Alves é inspiradora para a compressão das tramas simbólicas em torno de trajetórias artísticas em migração, para o desenvolvimento de referen- 
ciais teórico-metodológicos elucidativos do processo de modernização e de industrialização do simbólico no Brasil e, especialmente, para um esboço de uma genealogia/arqueologia da monumentalização do baião e de seus principais expoentes. Por essas razões, a obra se torna uma poderosa lente para a visualizarmos as distinções em torno do baião e o modo como ele se constituiu, para utilizamos os referenciais de Jacques Le Goff (2003), em um documento-monumento, uma construção repleta de interesses que projeta uma imposição voluntária ou involuntária de futuro:

\begin{abstract}
Resultado de uma montagem, consciente ou inconsciente, da história, da época, da sociedade que o produziram, mas também das épocas sucessivas durante as quais continuou a viver, talvez esquecido, durante as quais continuou a ser manipulado, ainda que pelo silêncio (Le Goff, 2003: 537-538).
\end{abstract}

\title{
Referências
}

ALVES, Elder P. Maia. A economia simbólica da cultura popular sertanejo-nordestina. Maceió: Edufal, 2011.

- A configuração moderna do sertão. Dissertação (Mestrado em Sociologia), Universidade de Brasília, 2004.

BOURDIEU, Pierre. A economia das trocas simbólicas. São Paulo: Perspectiva, 2005.

—. O poder simbólico. Rio de Janeiro: Bertrand, 2004.

ELIAS, Norbert. Mozart: sociologia de um gênio. Rio de Janeiro: Jorge Zahar, 1995.

HEYMANN, Luciana Quillet. Cinqüenta anos sem Vargas: reflexões acerca da construção de um "legado". XXVIII Encontro Anual da ANPOCS, Caxambu, 2004.

LE GOFF, Jacques. História e memória. Campinas: Editora Unicamp, 2003.

MOREIRA, Núbia Regina. A presença das compositoras no samba carioca: um estudo da trajetória de Teresa Cristina. Tese (Doutorado em Sociologia), Universidade de Brasília, 2013. 
